Yu.V. Batygin, E.A. Chaplygin, O.S. Sabokar, V.A. Strelnikova

\title{
ANALYSIS OF ELECTROMAGNETIC PROCESSES IN THE SYSTEM «CYLINDRICAL SOLENOID - MASSIVE CONDUCTOR»
}

\begin{abstract}
Purpose. Defining the key parameters of the inductor geometry, as a long multi-turn solenoid, that influence on the current amplitude induced excited in a massive conductor with a flat boundary surface. Methodology. Performing a mathematical analysis of the electrodynamic problem solution for an area with variable structure by integrating Maxwell's equation within the given boundary and initial conditions and also physical assumptions simplifying the process of solving but not distorting the result and carrying out an experiment that confirms not only the correctly construction considered but also the acceptability of the chosen assumption the opacity applying of the metal blank for these operating fields frequencies. Results. Functional dependencies of the current induced parameters on the metal surface of the heating object have been obtained, along which numerical estimates of the electrodynamic process have been performed, and key parameters influencing the heating efficiency have been determined. The correctness of the solutions obtained was confirmed experimentally. The final form of the solution function of the physical-mathematical problem was shown to be acceptable for performing further engineering and research calculations. Originality. The functional connection of the measured values of the induced surface current and the parameters of the measuring system is determined, the experimental confirmation of which indicates the satisfactory calculation model of the induction heating system and the entire solution as a whole. Practical value. Based on the calculations performed, working samples of inductive systems for induction heating that meet the specified heating rate and area requirements can be constructed. The obtained analytical expressions were transformed and simplified for their further using for engineering calculations with a minimum error value. References 8 , tables 1 , figures 4.

Key words: induction heating, Maxwell's equations, sheet metal, electromagnetic field, electrodynamic problem, eddy currents.
\end{abstract}

Цель. Определение ключевых параметров геометрии индуктора, как длинного многовиткового соленоида, влияющих на амплитуду индуцированного тока возбуждаемого в массивном проводнике с плоской граничной поверхностью. Методика. Выполнение математического анализа решения электродинамической задачи для среды с переменной структурой путем интегрирования уравнений Максвелла в рамках заданных граничных и начальньх условий, а также физических допущений, которые упрощают процесс решения, но не искажают его результат; а такље проведение эксперимента подтверждающего не только правильно выполненное построение, но и допустимость применения выбранного допущения о непрозрачности металлической заготовки для данных частот действующих полей. Результаты. Получены функциональные зависимости искомых параметров индуцированного тока на поверхности металла объекта нагрева, по которым были выполнены численные оценки электродинамического процесса, определены ключевые параметры, влияющие на эффективность нагрева. Правильность полученных решений была подтверждена экспериментально. Окончательный вид функции решения физико-математической задачи был приведен к приемлемому для выполнения дальнейших инженерных и исследовательских расчётов. Научная новизна. Определена функциональная связь измеряемых величин индуцированного поверхностного тока и параметров измерительной системы, экспериментальное подтверждение которой свидетельствует об удовлетворительности расчетной модели системы индукционного нагрева и всего решения в целом. Практическая значимость. На основании проведенных расчетов могут быть сконструированы рабочие образцы индуктивных систем для индукционного нагрева, отвечающие заданным требованиям скорости нагрева и его площади. Полученные аналитические выражсения были преобразованы и упрощены с целью их дальнейшего использования для инженерных расчётов с минимальной величиной погрешности. Библ. 8, табл. 1, рис. 4.

Ключевые слова: индукционный нагрев, уравнения Максвелла, листовой металл, электромагнитное поле, электродинамическая задача, вихревые токи

Introduction. The development proposed by the authors [1] with the use of induction local heating of metal surfaces assumes the fulfillment of research calculations of the field penetration process into sample sheet metal in order to determine its qualitative and quantitative characteristics.

Today, there are large number amount of research material covering the physical processes and the corresponding solutions to the problems of induction heating technologies. The author [2] describes the electrodynamic processes under metal cylinder heating and numerical values obtained coinciding with the experimental data. A similar model of the system is also described in [3] for heating the walls of a cylindrical surface to simulate the process of strips welding. No less significant are research into the microscopic parameters behavior of an object. The author [4], among other things, studied the effect of magnetic permeability and its changes on the efficiency of the metal heating for its heat treatment. The characteristic combining factor of the works analyzed, including similar ones $[5,6]$, is the orientation to objects of cylindrical geometry and a common mathematical apparatus, namely, the numerical analysis of FEM, by which it is impossible to obtain analytical dependencies suitable for engineering calculations.

Since in most cases induction heating is used for cylindrical objects heating processes, the application of the available recommendations for flat surfaces heating can lead to incorrect technical solutions in practice.

The analysis of the flat surfaces heating is an actual task for the further determination of the induction heating tools optimal parameters.

To obtain a general estimation of the electromagnetic interaction between the field source and

(C) Yu.V. Batygin, Ye.O. Chaplygin, O.S. Sabokar, V.A. Strelnikova 
the object, it is advisable to neglect the penetration processes, and to considered the metal of the billet as the ideal conductivity approximation.

To exclude all kinds of circumstances that occur in real constructions of inductor systems and to evaluate precisely the geometry of the relative location of the field source and the object of electromagnetic influence, it is advisable to neglect the penetration processes, and to consider the metal of the sample in the ideal conductivity approximation.

The goal of the paper is to define the key parameters of the inductor geometry, as a long multi-turn solenoid, that influence on the current amplitude induced excited in a massive conductor with a flat boundary surface.

Fields and the eddy currents. The computational model in the cylindrical coordinate system is shown in Fig. 1.

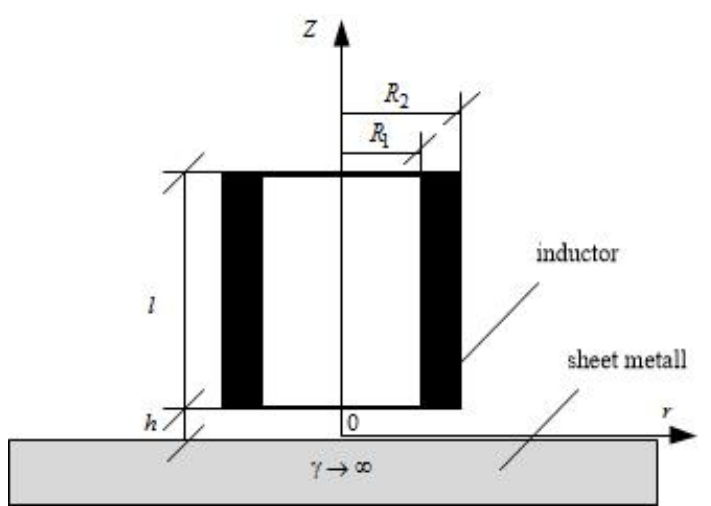

Fig. 1. The model of the inductor system with a long cylindrical inductor, above the ideally conducting blank.

Formulation of the problem:

- the system has an azimuthal symmetry, so that $\frac{\partial}{\partial \varphi}=0, \varphi-$ azimuth angle;

- the current in the winding of the inductor is represented by the azimuthal component with a uniformly distributed spatial density $-j_{\varphi}(t), t-$ time;

- electromagnetic processes in the system are quasisteady in the Landau sense, so that $\frac{\omega}{c} \cdot l>>1, \omega-$ cyclic frequency, $c$ - light speed in vacuum, $l-$ the largest characteristic size of the system [7].

- the metal of the inductor winding has not influence the flowing electromagnetic processes.

The solution carrying out of the problem is mannered according to the $[7,8]$.

The Maxwell's equations for non-zero components of electromagnetic field strengths, been transformed by Laplace taking into account zero initial conditions, at space above the blank, where $z \geq 0$, have a view [7]:

$$
\left\{\begin{array}{l}
\frac{\partial H_{r}(p, r, z)}{\partial z}-\frac{\partial H_{z}(p, r, z)}{\partial r}=j_{\varphi}(p, r, z) ; \\
\frac{1}{r} \cdot \frac{\partial}{\partial r}\left(r \cdot E_{\varphi}(p, r, z)\right)=-\mu_{0} \cdot p \cdot H_{z}(p, r, z) ; \\
\frac{\partial E_{\varphi}(p, r, z)}{\partial z}=\mu_{0} \cdot p \cdot H_{r}(p, r, z) ;
\end{array}\right.
$$

where $p$ - Laplace transform parameter;

$$
\begin{aligned}
& E_{\varphi}(p, r, z)=L\left\{E_{\varphi}(t, r, z)\right\}, \\
& H_{r, z}(p, r, z)=L\left\{H_{r, z}(t, r, z)\right\}, \\
& j_{\varphi}(p, r, z)=L\left\{j_{\varphi}(t, r, z)\right\} .
\end{aligned}
$$

In the general case, the current density on the righthand side of equation (1) is written as:

$$
j_{\varphi}(p, r, z)=\left(p \cdot \varepsilon_{0}+\gamma\right) \cdot E_{\varphi}(p, r, z)+j_{\varphi_{i}}(p, r, z),
$$

where $j_{\varphi_{i}}(t, r, z)$ - the inductor outside current density,

$$
j_{\varphi_{i}}(p, r, z)=j(p) \cdot f_{1}(r) \cdot f_{2}(z),
$$

$j(p)$ - amplitude-time dependence; $f_{1}(r)$ - the radial current distribution function in the inductor; $f_{2}(z)-$ the inductor current distribution function by variable $-z$; $\varepsilon_{0}-$ the dialectical vacuum permeability.

For a cylindrical inductor in Fig. 1 with a radial and longitudinal number of turns $-w_{r}, w_{z}$ accordingly, homogeneous distributions of the exciting current with respect to the spatial variables are described by the following functions.

$$
\left\{\begin{array}{l}
f_{1}(r)=\left[\eta\left(r-R_{1}\right)-\eta\left(r-R_{2}\right)\right] \\
f_{2}(r)=[\eta(z-h)-\eta(z-(h+l))]
\end{array},\right.
$$

where $R_{2}-R_{1}=w_{r} \cdot d, l=w_{z} \cdot d, d \times d$ - cross-sectional dimension of the square turn.

The amplitude-time dependence of the excitation current density is written as:

$$
j(p)=\frac{I(p)}{d^{2}},
$$

where $I(p)=L\{I(t)\}, I(t)-$ the inductor current,

$$
I(t)=I_{m} \cdot \psi(t),
$$

$I_{m}, \psi(t)$ - amplitude and time dependence, respectively.

From the Maxwell system (1) - (3) a differential equation for the azimuthal component of the electric field strength $E_{\varphi}(p, \lambda, z)$ can be obtained, which after the integral Fourier-Bessel transform takes the form [8].

The unknown constants can be defined from the boundedness conditions of the function $E_{\varphi}(p, \lambda, z)$ with $z \rightarrow \infty$ and its equality to zero on an ideally conducting surface $z=0$. Intermediate identical transformations are omitted because of its triviality and to avoid excessive unwieldiness in the material presentation.

In the end, it is found that

$$
E_{\varphi}(p, \lambda, z)=-\frac{K(p, \lambda)}{\lambda^{2}} \cdot e^{-\lambda h} \cdot\left(1-e^{-\lambda l}\right) \cdot \operatorname{sh}(\lambda z),
$$

where $\lambda$ - parameter of the Fourier-Bessel integral transformation; $J_{1}(\lambda \cdot r)$ - the first order Bessel function,

$$
K(p, \lambda)=\mu_{0} \cdot p \cdot j(p) \cdot F(\lambda),
$$

where $F(\lambda)=\int_{R_{1}}^{R_{2}} r J_{1}(\lambda \cdot r) d r \quad-$ the radial current distribution Fourier-Bessel image function in the inductor $-f_{1}(r)$ from $(5)$.

Using (3) and (7), taking into account the quantities presented in (8), and the Fourier-Bessel image of the tangential component of the magnetic field intensity in the region $z<0$ is determined as 


$$
H_{r}(p, \lambda, z)=-\frac{j(p)}{\lambda} \cdot F(\lambda) \cdot e^{-\lambda h} \cdot\left(1-e^{-\lambda l}\right) \cdot \operatorname{ch}(\lambda z) .
$$

The current density module on the surface of the ideally conducting workpiece $-j_{\varphi}(p, \lambda)$ is equal to the modulus of the magnetic field strength tangential component [2].

Using (8), taking into account (6) after inverse Fourier-Bessel and Laplace transforms, it is found that

$$
\begin{aligned}
& j_{\varphi}(t, r)=-\frac{I_{m}}{d^{2}} \cdot \psi(t) \times \\
& \times \int_{0}^{\infty} F(\lambda) \cdot e^{-\lambda h} \cdot\left(1-e^{-\lambda l}\right) \cdot J_{1}(\lambda r) d \lambda .
\end{aligned}
$$

The eddy current in the circular region of the radius $R$ is found by integrating expression (9) for $r \in[0 ; R]$ :

$$
\begin{aligned}
& I_{\varphi}(t, r \leq R)=-I_{m} \cdot \psi(t) \cdot \int_{0}^{\infty} \frac{F(\lambda)}{(\lambda d)} \cdot e^{-\lambda h} \times \\
& \times\left(1-e^{-\lambda l}\right) \cdot\left(1-J_{0}(\lambda R)\right) d \lambda .
\end{aligned}
$$

We reduce the formula (9), (10) to a form converted for practical estimates. Thus, in terms of the new integration variable, the expressions (9) and (10) are transformed to the form of the following dependencies:

a) relative density of current induced,

$$
\begin{gathered}
J_{0}(r)=\frac{j_{\varphi m}}{\left(\frac{I_{m}}{d}\right)}= \\
=\int_{0}^{\infty} F(x) \cdot e^{-x \cdot \frac{h}{d}} \cdot\left(1-e^{-x \cdot \frac{l}{d}}\right) \cdot J_{1}\left(x \cdot \frac{R_{1}}{d} \cdot\left(\frac{r}{R_{1}}\right)\right) d x,
\end{gathered}
$$$$
\text { where } F(x)=\frac{1}{x^{2}} \cdot\left(x \cdot \frac{R_{2}}{d}\right)
$$$$
\left(x \cdot \frac{R_{1}}{d}\right)
$$

b) relative magnitude of the current induced (current transformation ratio),

$$
\begin{aligned}
I_{0}(R)= & \frac{I_{\varphi m}}{I_{m}}=\int_{0}^{\infty} \frac{F(x)}{x} \cdot e^{-x \cdot \frac{h}{d}} \cdot\left(1-e^{-x \cdot \frac{l}{d}}\right) \times \\
& \times\left(1-J_{0}\left(x \cdot \frac{R_{1}}{d} \cdot\left(\frac{R}{R_{1}}\right)\right)\right) d x .
\end{aligned}
$$

In reality, the turns are separated by dielectric gaps. Let it be the same and equal in the vertical and horizontal directions $\Delta$. Concerning, the geometric parameters of the inductor can be determined by the following relations:

$$
\left\{\begin{array}{l}
l=w_{l} \cdot\left[d+\Delta \cdot\left(1-\frac{1}{w_{l}}\right)\right] \\
R_{2}=R_{1}+w_{r} \cdot\left[d+\Delta \cdot\left(1-\frac{1}{w_{r}}\right)\right] .
\end{array}\right.
$$

Taking into account (13), the expressions (11) and (12) take the next forms:
a) relative density of the current induced,

$$
\begin{gathered}
J_{0}(r)=\frac{j_{\varphi m}}{\left(\frac{I_{m}}{d}\right)}= \\
=\int_{0}^{\infty} F(x) \cdot e^{-x \cdot \frac{h}{d}} \cdot\left(1-e^{\left.-x \cdot \frac{l}{d}\right)} \cdot J_{1}\left(x \cdot \frac{R_{1}}{d} \cdot \rho\right) d x .\right.
\end{gathered}
$$

b) relative magnitude of the current induced in the region of radius $-R$ (current transformation ratio respectively),

$$
\begin{aligned}
& I_{0}\left(R_{0}\right)=\frac{I_{\varphi m}}{I_{m}}=\frac{1}{N_{m}} \cdot \int_{0}^{\infty} \frac{F(x)}{x} \times \\
& \times e^{-x \cdot \frac{h}{d}\left(1-e^{-x \cdot \frac{l}{d}}\right) \cdot\left(1-J_{0}\left(x \cdot \frac{R_{1}}{d} \cdot R_{0}\right)\right) d x,}
\end{aligned}
$$

where

$$
N_{m}=\left(1+\frac{\Delta}{d} \cdot\left(1-\frac{1}{w_{l}}\right)\right) \cdot\left(1+\frac{\Delta}{d} \cdot\left(1-\frac{1}{w_{r}}\right)\right), R_{0}=\frac{R}{R_{1}} .
$$

Numerical estimations of the excitation processes efficiency for eddy currents are given in the example for the system with the following parameters: $R_{1}=0.02 \mathrm{~m}$, $d=0.002 \mathrm{~m}, \Delta=0.0005 \div 0.001 \mathrm{~m}, h=0.001 \mathrm{~m}$.

There are indices off induction processes for windings with the number of turns in one row equal to $w_{l, r}=10$ (Table 1$)$.

Table 1

Numerical estimations

\begin{tabular}{|c|c|c|c|c|}
\hline No. & $\begin{array}{c}\text { Wire row } \\
\text { quantity }\end{array}$ & $\begin{array}{c}\text { Wire } \\
\text { turns } \\
\text { common } \\
\text { quantity }\end{array}$ & $\begin{array}{c}\text { Cylindrical } \\
\text { inductor, } \\
\text { Relative } \\
\text { current }\end{array}$ & $\begin{array}{c}\text { Flat circular } \\
\text { inductor, } \\
\text { Relative } \\
\text { current }\end{array}$ \\
\hline 1 & 1 & 10 & 4.6 & 9.35 \\
\hline 2 & 2 & 20 & 9.5 & 16.2 \\
\hline 3 & 3 & 30 & 14.6 & 22.4 \\
\hline
\end{tabular}

Fig. 2 shows the situation with increasing number of turns in one row of winding up to $w_{l, r}=20$.

Experiment. To confirm the correctness of the calculations performed, similar experimental measurements for a similar electrodynamic system took place. The purpose of the following experiment is:

- the veracity confirmation about the consideration of the ideal conductor system;

- the veracity confirmation of the graphs obtained for induced current density distribution.

It is necessary to carry out two types of measurements for this. The measurement of the distribution of induced currents using an induction sensor located and moved along the radius of the conductor surface and the direct measurement of the induced current density by the voltage drop at a given gap in the conductor. The assumption about the ideal conductor makes it possible to affirm that the density of induced currents on the ideal conductor surface is equal numerically to the magnetic field strength above the conductor. Its veracity can be confirmed with the following scheme of the experiment.

The Fig. 3 below shows a schematic diagram of a contact measuring method. 


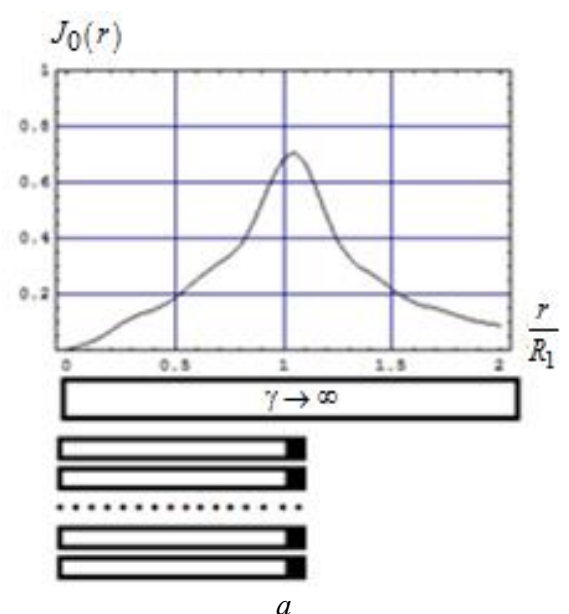

$$
I_{0}(r)
$$
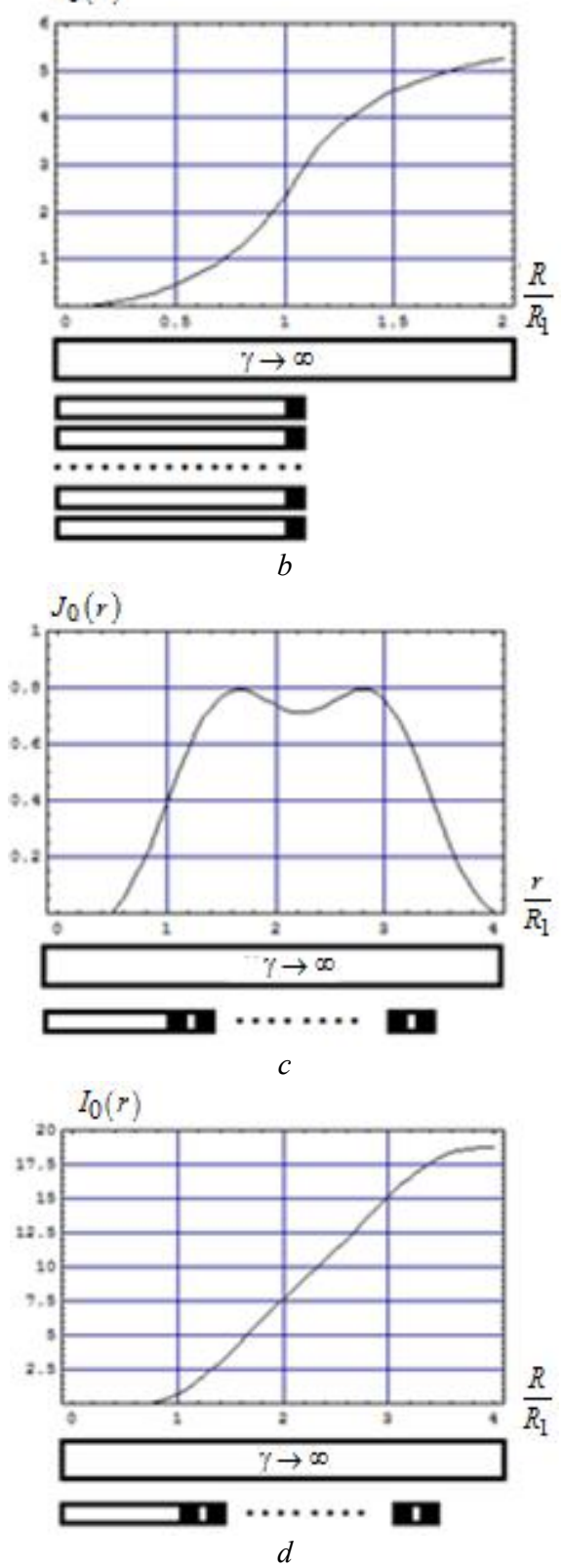

Fig. 2. Radial distributions of process efficiency indicators of eddy currents in inductors with single-layer windings,

$a, b$ - relative density and relative magnitude of the induced current, respectively, for $w_{l}=20, w_{r}=1$;

$c, d$-relative density and relative magnitude of the induced current, respectively, for $w_{l}=1, w_{r}=20$

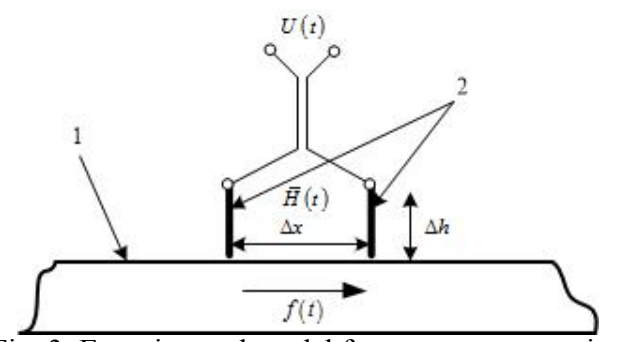

Fig. 3. Experimental model for contacts measuring

- Diameters of inductors used: cylindrical inductor $45 \mathrm{~mm}$, disk inductor $112 \mathrm{~mm}$;

- Height of inductors used: cylindrical inductor $50 \mathrm{~mm}$, disc inductor $-2 \mathrm{~mm}$;

- Number of turns inductors: 20 ;

- Inductor current frequency: $20.56 \mathrm{kHz}$;

- The amplitude of the inductor current: $16.8 \mathrm{~A}$;

- Conductivity of sheet billet: $\gamma=59.5 \cdot 10^{6} \mathrm{Sm} / \mathrm{m}$;

- The value of the contact gap: $\Delta x=5 \mathrm{~mm}$;

- Cross-sectional area of the contact contour and the inductive sensor: $S=5 \mathrm{~mm}^{2}$;

- Number of the inductive sensor coil turns: $N=100$.

It should be taken into account that the voltage measured at the contacts is the sum of the voltage drop and the induced EMF in the contact contour formed. According to this it's possible to determine the function of the measured voltage by the following formula

$$
U(t)=k_{1} j(t)+k_{2} \frac{d j(t)}{d t},
$$

where $k_{1}=\frac{\Delta}{\gamma}=\frac{5 \cdot 10^{-3}}{59.5 \cdot 10^{6}}=0.084 \cdot 10^{-9}$,

$$
k_{2}=\mu_{0} S N=100 \cdot 4 \pi \cdot 10^{-7} \cdot 5 \cdot 10^{-6}=1.57 \cdot 10^{-10}
$$

The solution of the resulting differential equation is the sought-for function of the current density on the metal surface

$$
\begin{aligned}
& j(t)=\frac{U_{m} \omega}{k_{2}\left(\omega^{2}+k_{12}^{2}\right)} e^{-k_{12} t}+\frac{U_{m}}{k_{2}\left(\omega^{2}+k_{12}^{2}\right)} \times \\
& \times\left(k_{12} \sin (\omega t)-\omega \cos (\omega t)\right),
\end{aligned}
$$

where $k_{12}=k_{1} / k_{2}$.

Taking into account the shape of the exciter current of the inductor and the signal measured, it is fairly to measure the amplitude of the induced current - the maximum of the signal. Neglecting the aperiodic component of the general solution, which eventually tends to zero, the sought-for value can be calculated as

$$
j_{m}=\frac{U_{m}}{k_{2} \sqrt{\left(\omega^{2}+k_{12}^{2}\right)}},
$$

In its turn, the induced current measured by the induction sensor should give the same value as in the case of the contact measurement method.

$$
\begin{gathered}
\xi(t)=\mu_{0} S_{S} N \frac{d H(t)}{d t} \approx \mu_{0} S_{S} N \frac{d j(t)}{d t}, \\
j(t)=\frac{1}{\mu_{0} S_{S} N} \int \xi(t) d t=\left|\xi(t)=\xi_{m} \sin (\omega t)\right|= \\
=\frac{\xi_{m}}{\mu_{0} S_{S} N \omega} \cos (\omega t)
\end{gathered}
$$

where $N$ - number of sensor coil turns; $S_{S}$ - sensor crosssectional area.

Fig. 4 shows the distribution of the induced current and its radial density with two different measurement methods. 

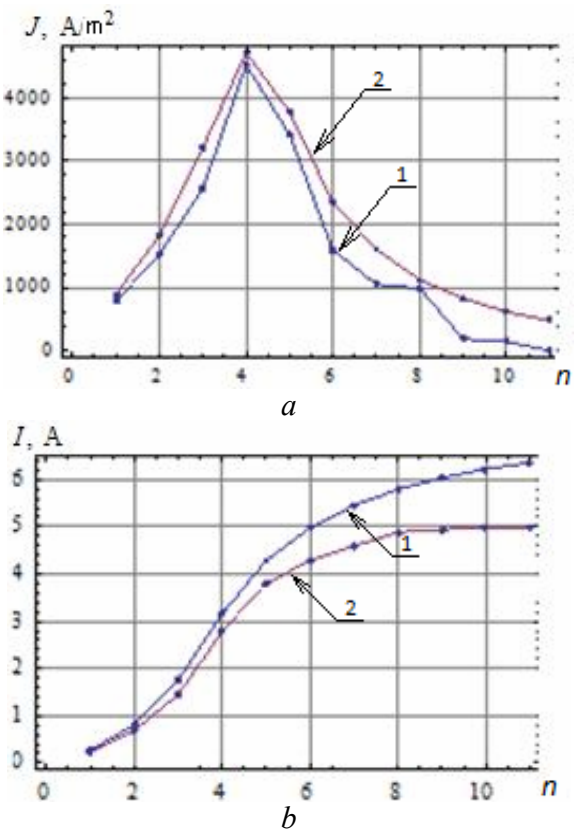

$J, \mathrm{Am}^{2}$
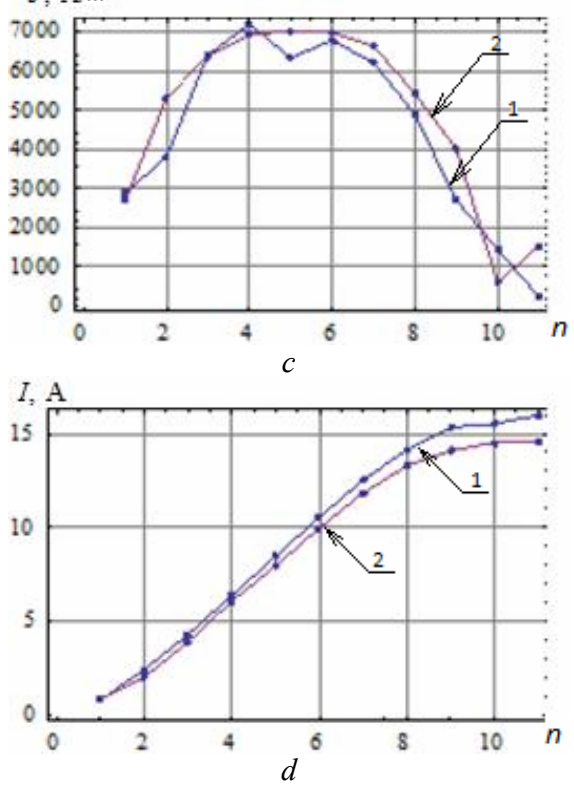

Fig.4. Radial distributions of process efficiency indicators of eddy currents in inductors with single-layer windings: $a, b$ - density and relative magnitude of the induced current, respectively, for $w_{l}=20, w_{r}=1$;

$c, d$-density and relative magnitude of the induced current, respectively, for $w_{l}=1, w_{r}=20$; measurements performed by: 1 - induction sensor, 2 - contact method

The qualitative and quantitative coincidence of the current density distributions measured and the calculated currents values for two different measurement methods allow to state the correct representation of the electrodynamic process model and the acceptability of the analytical dependences obtained.

Conclusions. The calculations carried out related for effective systems creation not only for the induction heating of thin-walled metals, but also for a number of electrical devices that represent air current transformers in this case.
The value of the current transformation coefficient depends essentially on the mutual arrangement of the inductor turns.

The most effective is to increase the radial number of turns, with a linear increase in the transmission coefficient. In turn, an increase in the turns along the vertical direction from the surface of the metal does not lead to a substantial transformation coefficient increasing due to the selfshielding effect of the winding.

In the case of a cylindrical inductor, the radial distribution of the excited currents has a pronounced maximum that coincides with the center at the end of the winding. For the practice of induction heating, it means a quadratic dependence of the heat emitting in this region of sheet metal.

The objectivity of the assumption of considering a massive conductor as an ideally conducting surface, as well as the reliability of the graphical dependencies obtained, were confirmed experimentally.

\section{REFERENCES}

1. Batygin Yu.V., Gnatov A.V., Chaplygin Ye.O., Sabokar O.S. Sposib indukcijnogo nagrivu dlja remontu metalevyh elementiv avtomobil'nyh konstrukcij [Method of induction heating for repair of the metal automobile constructions elements]. Patent UA, no.103494, 2015. (Ukr).

2. Kennedy M.W. Magnetic fields and induced power in the induction heating of aluminium billets. Licentiate Thesis. Royal Institute of Technology, Stockholm, $2013.70 \mathrm{p}$.

3. Wright J. Principles of high frequency induction tube welding. Washington Electronic Heating Equipment Inc., 1997. 8 p.

4. Klonk S. Modélisation Numérique du Chauffage par Induction de Pièces à Géométrie Complexe. [Numerical modelling of induction heating for complex geometrical parts]. Thèse pour obtenir le grade de docteur délivré. Doctorat Paris Tech. Paris, 2013. 186 p. (French).

5. Korshikov S.E. Optimal'noye upravleniye temperaturnymi rezhimami induktsionnogo nagreva tsilindricheskikh slitkov $s$ uchetom tekhnologicheskikh ogranicheniy. Diss. kand. techn. nauk [Optimum control of temperature modes of cylindrical ingots induction heating taking into account technological limitations. Cand. tech. sci. diss.]. Samara, 2015. 153 p. (Rus).

6. Dershpak N.S. The modes of induction heating of cylindrical parts connected with tension fitting. Technical electrodynamics, 2009, no.6, pp. 61-65. (Ukr).

7. Batygin Yu.V., Lavinskiy V.I., Khimenko L.T. Impul'snyve magnitnyye polya dlya progressivnykh tekhnologiy. Tom 1. Izdaniye vtoroye, pererabotannoye $i$ dopolnennoye. [Pulsed magnetic fields for advanced technologies. Vol.1. 2nd edition, revised and enlarged.] Kharkov, MOST-Tornado Publ., 2003. 284 p. (Rus).

8. Shneerson G.A. Polya i perehodnye processy v apparature sverhsilnyh tokov [Fields and transients in equipment ultra strong currents]. Moscow, Energoatomizdat Publ., 1992, 413 p. (Rus).

\section{Received 03.11.2017}

Yu.V. Batygin ${ }^{1}$, Doctor of Technical Sciences, Professor, Chaplygin E.A. ${ }^{1}$, Candidate of Technical Sciences, Associate Professor,

Sabokar O.S. ${ }^{1}$, Postgraduate Student,

Strelnikova V.A. ${ }^{1}$, Postgraduate Student,

${ }^{1}$ Kharkiv National Automobile and Highway University,

25, Yaroslava Mudrogo Str., Kharkiv, 61002, Ukraine. phone +380 577073727 ,

e-mail: yu.v.batygin@gmail.com, chaplygin.e.a@gmail.com, o.s.sabokar@gmail.com,v.strelnikova91@gmail.com

How to cite this article:

Batygin Yu.V., Chaplygin E.A., Sabokar O.S., Strelnikova V.A. Analysis of electromagnetic processes in the system «cylindrical solenoid - massive conductor». Electrical engineering \& electromechanics, 2018, no.1, pp. 54-58. doi: 10.20998/2074-272X.2018.1.08. 